\title{
G Research SGuare \\ The effect on lower limbs of wearing ankle weights in people under/over 70 years old: single comparison after intervention
}

Hiroyasu Akatsu ( $\nabla$ akatu@med.nagoya-cu.ac.jp )

Department of Community-based Medical Education, Nagoya City University Graduate School of Medicine

\section{Toshie Manabe}

Division of Community and Family Medicine, Center for Community Medicine, Jichi Medical University

\section{Yoshihiro Kawade}

Department of Community-based Medical Education, Nagoya City University Graduate School of Medicine

\section{Yoshiyuki Masaki}

Asuke Hospital,

\section{Shigeru Hoshino}

Gamagori Municipal Hospital

\section{Takashi Jo}

Gamagori Municipal Hospital

\section{Shinya Kobayashi}

Asuke Hospital,

\section{Tomihiro Hayakawa}

Asuke Hospital,

\section{Hirotaka Ohara}

Department of Community-based Medical Education, Nagoya City University Graduate School of Medicine

\section{Research Article}

Keywords: 30-second chair stand test (CS-30), fall prevention, frailty, resistance training

Posted Date: March 4th, 2021

DOI: https://doi.org/10.21203/rs.3.rs-273082/v1

License: (c) (i) This work is licensed under a Creative Commons Attribution 4.0 International License.

Read Full License 


\section{Abstract \\ Background}

Since the emergence of Coronavirus disease 2019 (COVID-19), safety management in gymnastics classrooms has been difficult. As a result, healthy older adults are more likely to voluntarily refrain from attending because of fear of contracting COVID-19, and thus engage in less exercise. In this context, it is important to develop methods for self-prevention of frailty that can be conducted safely and easily at home. We examined the effectiveness of providing ankle weights to older adults as a frailty prevention device.

\section{Methods}

All participants were 50-90 years old and were screened for falls using the Motor Fitness Scale (MFS). Participants were divided into two groups ( $\leq 70$ and $\geq 71$ years old) and analyzed. We rented ankle weights for 3 months to older adults in the community and evaluated changes in physical and motor function before and after wearing them.

A total of 75 people who responded to the call for participants used ankle weights for 3 months, and underwent various measures of physical condition, cognitive condition, and performance (body composition, grip strength, standing on one leg with eyes open, 30-second chair stand test [CS-30], timed up-and-go test [TUG], walking speed, body sway measurement, and the Japanese version of Montreal Cognitive Assessment [MOCA-J]) before and 3 months after wearing ankle weights.

\section{Results}

CS-30 performance improved in both younger and older participants.

\section{Conclusions}

CS-30 reflects lower limb/trunk muscle strength and can be used as an index of fall risk. Our results suggest that wearing ankle weights can be recommended as a fall-prevention measure.

\section{Trial registration:}

University hospital Medical Information Network ID 000038073) and registration date at April 14th 2020

\section{Background}


Prevention of fractures and falls among older adults is an urgent priority, and can help avoid the need for long-term care, extend healthy life expectancy, and further reduce medical and nursing care costs.

While various exercise interventions are commonly practiced among older adults living in the community, it has been reported that improving physical balance is most important for fall prevention. ${ }^{1}$ Falls among older adults can be reduced by exercise interventions, particularly balance improvement exercises and various types of combination exercises. ${ }^{2}$ It has been reported that instructor-led gymnastics classrooms are safer and more effective than self-directed efforts and self-judgment, and are more suitable for improving physical function than exercising at home. ${ }^{3}$ However, widespread distribution of such classrooms as part of health safeguarding cannot be expected in the near future because of shortfalls in systems, facilities, staffing, and cost, including the cost performance index. Furthermore, in the global context of the Coronavirus disease 2019 (COVID-19) pandemic, it is extremely difficult to conduct gymnastics classes that require physical gatherings of individuals. Older adults need to stay at home to avoid the risk of infection, which can increase the risk of falls and lead to increased frailty.

From this perspective, as a familiar and easy resistance exercise, we focused on home exercises using weights attached to the ankles to improve lower limb muscle strength and maintain balance.

Wearing ankle weights (AWs) on the ankles while walking is reported as a method for increasing physical activity intensity that has been used [1]. This equipment is widely available in sports stores as consumer products, and is commonly used for lower limb training by younger adults. A previous study evaluated oxygen uptake as a systemic physiological index while applying different levels of load by wearing AWs of different weights [2].

However, the effects of resistance exercises on lower limbs and preventing physical function decline have not yet been elucidated. The aim of this prospective study was to assess whether AWs can improve body composition or performance, and to examine the feasibility of AWs for further investigations.

\section{Methods}

\section{Study design, sites, and participants}

We conducted a prospective paired study (with/without feedback) at three sites in Japan: The Community Health Education and Research Center (CHC) of Nagoya City University, Asuke Hospital, and Gamagori Municipal Hospital in Aichi. Figure S1 shows the flowchart of participants at the briefing.

Participants were healthy volunteers who lived in the towns surrounding the study sites. We recruited subjects using posters and brochures for $\mathrm{CHC}$ 's health measurement program. All participants were 50-90 years old, scored $\geq 11$ points (men) or $\geq 9$ points (women) on the Motor Fitness Scale (MFS), ${ }^{5}$ were able to accurately respond to questions asked in a consultation with a physician, and agreed to participate in the present study. The number of applicants who gathered at the time of the 
initial meeting and carried on to registration after the final interview and screening tests is presented as supplementary data (Fig. S1).

The study was approved by the Institutional Review Board of Nagoya City University (46-18-0006) and registered University hospital Medical Information Network (UMIN, ID 000038073) April 14th 2020. Each participant provided written informed consent.

The investigators kept the datasets in password-protected systems and maintained the anonymity of study participants in all presentations of the data.

\section{Schedule and recording daily activity}

Two cohorts were randomly assigned to two groups using an envelope method in each area; one group underwent individual interviews (group I) for observing behavioral changes, and the other group did not undergo individual interviews (group II). In the current study, we analyzed group I and II separately, and both groups together, and compared changes between before and after.

Figure 1 shows the flowchart of the study after obtaining consent and registration.

After obtaining consent, conducting the Motor Fitness Scale (MFS), and collecting participants' clinical history, the first measurements were performed.

After observation for 4 weeks, further measurements were performed (2nd), followed by the intervention for 12 weeks. The final measurement was performed after the intervention ( $3 r d)$. In the current study, we analyzed the data before (2nd) and after (3rd) the intervention.

The weight of an AW is based on $2 \%$ of body weight.

Because ready-made commercially produced AWs (0.5 kg: KW-505,0.8, 1 kg: KW-506, 1.5 kg: KW-507, IRONMAN CLUB, Taiwan) weigh $0.5,0.8,1.0$, and $1.5 \mathrm{~kg}$ per lateral ankle only, it is impossible to set the exact weight according to body weight.

The actual weight was decided upon by each individual after pre-wearing the AW for 5-10 minutes.

As an intervention rule, we set a lower limit of one 20-minute session of outdoor walking per day while wearing AWs, at least twice a week, for 12 weeks.

Participants were free to wear the AWs at other times without any upper limit.

It was also possible for participants to change the weight if it did not adequately match their body weight.

During the intervention period, we asked participants to record daily activity of AW use.

At this time, we conducted individual interviews with members of group I concerning AW-wearing status, physical problems, and advice of various types (thin arrow in Fig. 1).

The first physical and fitness measurements were performed immediately after enrollment (dark arrow in Fig. 1), followed by a 4-week pre-observation period (data not reported). 
The second measurement period was then performed while participants wore AWs for 12 weeks. The third measurements were conducted after 12 weeks. Thereafter, the post-observation period is scheduled to continue until the final measurement, planned for 1 year after the initial measurement. In the current study, we analyzed the results of the second and third (pre-and post-intervention) measurements performed thus far.

\section{Questionnaire survey on lifestyle}

Data on participants' demographic and clinical characteristics, including age, sex, profession, living situation, underlying diseases, medications, smoking and alcohol intake, and sleep quality, were collected during clinical consultations with physicians using an original questionnaire designed by the study investigators.

Furthermore, as daily activities, participation in gymnastics classes, yoga, walking, dancing, swimming, and the presence or absence of sports activities such as tennis, baseball, and golf were also collected.

\section{Muscle measurements}

Multiple measures of executive function were assessed. Body composition parameters, including lower leg circumference and skeletal muscle mass, were assessed using multi-frequency bioelectrical impedance with an In Body device (In Body Japan, Tokyo, Japan). ${ }^{6}$ Although there were differences in the generation of the model at each facility (as shown in supplementary data), there were no differences in data acquisition and analysis.

The skeletal muscle mass index (SMI) was derived as the sum of the muscle mass of the four limbs (right arm, left arm, right leg, and left leg muscles) divided by the square of height $\left(\mathrm{kg} / \mathrm{m}^{2}\right) .{ }^{7}$ Grip strength was reported as a representative indicator [3], measured with a conventional grip dynamometer (YO2, Tsutsumi Seisakusho Co., Ltd, Chiba, Japan) to assess muscular strength. We hypothesized that muscles related to respiration and swallowing would be strengthened by lower leg muscle building. Respiratory function was measured via physiological examinations in each hospital and tongue pressure measurement was performed using an Orarize device (JMS, Hiroshima, Japan).

\section{Balance and mobility tests}

Three measures of balance and mobility (the one-leg standing test [OLST], ${ }^{8}$ timed up-and-go test [TUG], 9 and 30 -second chair stand test $[\mathrm{CS}-30]^{10}$ ) were assessed.

The OLST is a balance assessment method used for older adults. ${ }^{8}$ In the current study, the rater instructed participants to stand on one leg with their upper limbs hanging downward and their eyes open, without specifying any conditions for lifting the other leg. The measurement, with 120 seconds as the longest measurement time, was conducted twice for each lower limb (affected and unaffected sides), and the highest value was recorded. 
The 3.0-meter TUG measures coordination, agility, balance, and speed. ${ }^{9}$ Participants begin from a fully seated position with their feet flat on the ground. At the start of the test, participants are instructed to stand up and walk as quickly as possible, without running, around a cone placed 3.0 meters in front of a chair and then to return to their initial seated position in the chair. In our study, the shorter time of two trials was used for the analysis. The TUG was also performed at normal walking speed. A stopwatch was used to assess the time of each trial.

The CS-30 measures lower extremity strength [4]. A chair with a seat height of $40-\mathrm{cm}$ was used for the assessment [4].

The starting position of participants was standardized with regard to buttock placement, back support, use of hands, and foot placement.

The participants were instructed to cross their arms at the wrists and hold them against their chest.

Participants were asked to sit and stand as many times as possible in 30 seconds.

The total number of completed chair stands within 30 seconds was then counted and recorded.

Furthermore, balance function was analyzed using the Gravicorder sway meter for the center of gravity (Anima, Tokyo, Japan). Although there is a difference in the generation of the model at each facility, the acquisition and analysis of the sway of the center of gravity were unified using the Gravicorder device.

\section{Statistical analysis}

A similar number of participants were under and over 70 years old, which was close to the mean age of participants.

Participants were divided into two groups ( $\leq 70$ and $\geq 71$ years old).

Data were expressed as median and interquartile range (25th to 75th percentile) or as mean and standard deviation (SD) for continuous variables, and proportions were used for categorical variables.

Participants were divided into two groups, aged $\leq 70$ (younger group) or $\geq 71$ years (older group).

In addition, participants were divided into two groups on the basis of the SMI criteria defined by the Asian Working Group for Sarcopenia (AWGS) ${ }^{7}$ : normal SMl: $\geq 7.0 \mathrm{~kg} / \mathrm{m}^{2}$ (men), $\geq 5.7 \mathrm{~kg} / \mathrm{m}^{2}$ (women); low SMl: $<7.0 \mathrm{~kg} / \mathrm{m}^{2}$ (men), $<5.7 \mathrm{~kg} / \mathrm{m}^{2}$ (women). The AWGS proposes measurement of SMI in older adults (aged $\geq 65$ years) with low grip strength (men $<26 \mathrm{~kg}$, women $<18 \mathrm{~kg}$ ) or slow walking speed $(\leq 0.8 \mathrm{~m} / \mathrm{s}$ ), and a diagnosis of sarcopenia is made if low SMI (as defined above) is detected. ${ }^{7}$ Comparisons were made between these two groups using the $\chi^{2}$ test or Fisher's exact test for categorical variables, and the MannWhitney Utest or Student's $t$-test for continuous variables. We examined the correlations between age, physical measurement, muscular strength, and balance and mobility tests using Pearson's correlation coefficients. Possible factors influencing SMI were determined using logistic regression analysis with independent variables of age, sex, body mass index, chest circumference, hand grip strength, OLST, 3.0-m walk test, TUG (normal), TUG (fast), and CS-30 performance. A stepwise selection method was used to select variables. 
Data were analyzed using IBM SPSS, Version 25.0 (IBM, Armonk, NY, USA). For all analyses, significance levels were two-tailed, and $P<0.05$ was considered statistically significant.

\section{Results}

\section{Background overview and harmful events during the intervention}

Ninety-nine people participated in the information session, and consent was obtained from 74 individuals.

In the MFS questionnaire, all participants achieved a passing score in the initial measurement. However, one participant withdrew, and 73 participants began the study.

There were no dropouts during the examination period, but one incident occurred, in which a participant lost balance after taking off the AW and sustained a bruised face.

After consulting a general physician, no problems were identified, and the participant was able to continue with the trial.

Participants' general background information is shown in Table 1.

Overall, 73 people aged 66-76 years (median 71 years) participated, $25 \%$ of whom were male and most of whom were homemakers or retirees.

Few participants had ever smoked, and more than half reported having some sleep difficulties.

Of the more than $40 \%$ of people who had been hospitalized, more than half received medication for an underlying disease (Table 1). 
Table 1

General characteristics of participants

\begin{tabular}{|ll|}
\hline & $\mathrm{N}=73$ \\
\hline General conditions & \\
\hline Age, years, median (IQR) & $71(66-76)$ \\
\hline age $\geq 71, \mathrm{n}(\%)$ & $37(50.7)$ \\
\hline Gender-male, $\mathrm{n}(\%)$ & $18(24.7)$ \\
\hline Living conditions & \\
\hline Living with family, $\mathrm{n}(\%)$ & $58(79.5)$ \\
\hline Profession & \\
\hline Employee & $3(4.1)$ \\
\hline Self-employed person & $2(2.7)$ \\
\hline Homemaker & $27(37.0)$ \\
\hline Retiree & $25(34.2)$ \\
\hline Part time job & $11(15.1)$ \\
\hline Others & $4(5.5)$ \\
\hline Habitation & \\
\hline Smoking history, $\mathrm{n}(\%)$ & $6(8.2)$ \\
\hline Drinking alcohol, $\mathrm{n}(\%)$ & $27(37.0)$ \\
\hline Having problems with Sleep, $\mathrm{n}(\%)$ & $35(47.9)$ \\
\hline Clinical conditions & $46(63.0)$ \\
\hline $1 \geq 0$ of underlying disease, $\mathrm{n}(\%)(\mathrm{n}=71)$ & \\
\hline Experience of hospitalization, $\mathrm{n}(\%)$ & $(62.5)$ \\
\hline Taking prescription medication, $\mathrm{n}(\%)(\mathrm{n}=72)$ \\
\hline
\end{tabular}

The factors of age, physical measurement, muscular strength, and balance and mobility tests exhibited no correlations using Pearson's coefficients. In addition, although the data were not reported in this study, there were individual differences in the presence or absence of sports activities.

\section{Changes in body composition before and after intervention}

Changes in body composition during the intervention are shown in Table 2, with measurements by In Body. There were minor changes in physical composition. SMI was calculated in 44 cases automatically 
in the $\mathrm{CHC}$, and significantly decreased after intervention in both the younger and older groups.

Table 2

Body composition among participants before and after intervention

\begin{tabular}{|c|c|c|c|c|c|c|}
\hline & $\begin{array}{l}\text { Age, } \leq 70 \\
n=36\end{array}$ & & & $\begin{array}{l}\text { Age, } \geq 71 \\
n=37\end{array}$ & & \\
\hline Parameters-mean(SD) & Before & After & $P$ value & Before & After & $P$ value \\
\hline BMI & $23.0(3.4)$ & $23.0(3.3)$ & 0.908 & $22.1(2.3)$ & $22.2(2.3)$ & 0.318 \\
\hline Body fat $\%$ & $29.3(8.3)$ & $28.9(8.1)$ & 0.220 & $28.2(7.0)$ & $28.1(7.2)$ & 0.941 \\
\hline Muscle mass & $38.8(7.4)$ & $39.1(7.8)$ & 0.176 & $36.0(7.5)$ & $36.1(7.2)$ & 0.698 \\
\hline Skeletal muscle mass & $22.2(4.6)$ & $22.4(4.9)$ & 0.104 & $20.4(4.6)$ & $20.5(4.5)$ & 0.490 \\
\hline Right arm muscle mass & $2.0(0.6)$ & $2.0(0.5)$ & 0.722 & $1.8(0.6)$ & $1.8(0.6)$ & 0.075 \\
\hline Left arm muscle mass & $2.0(0.6)$ & $2.0(0.5)$ & 0.865 & $1.8(0.5)$ & $1.8(0.5)$ & 0.097 \\
\hline Trunk muscle mass & $18.0(3.6)$ & $18.0(3.3)$ & 0.985 & $16.6(3.4)$ & $16.7(3.4)$ & 0.065 \\
\hline Right leg muscle mass & $6.4(1.5)$ & $6.6(1.7)$ & 0.287 & $5.8(1.5)$ & $5.8(1.5)$ & 0.738 \\
\hline Left leg muscle mass & $6.4(1.5)$ & $6.5(1.7)$ & 0.310 & $5.8(1.5)$ & $5.8(1.4)$ & 0.596 \\
\hline SMI $(n=22)$ & $6.5(0.9)$ & $6.4(0.9)$ & $\star 0.045$ & $6.3(1.0)$ & $6.2(0.9)$ & $* 0.024$ \\
\hline
\end{tabular}

\section{Anthropometry}

General anthropometry results are presented in the top third of Table 3. The lower limb circumference in older subjects significantly increased. There was no change in blood pressure or heart rate. 
Table 3

Changes in results of performance tests and standing position balance before versus after intervention

Age, $\leq 70$

$\mathrm{n}=\mathbf{3 6}$

Parameters-mean(SD)

Anthropometry

Calf circumference

Right

Before
$39.2(8.2)$

$35.1(2.6)$
Age, $\geq 71$

$\mathrm{n}=\mathbf{3 7}$

After

\begin{tabular}{|c|c|c|}
\hline & $\mathrm{n}=37$ & \\
\hline$P$ & Before & After \\
\hline
\end{tabular}

Left

Left
$\begin{aligned} & \text { Blood pressure }(\mathrm{mmHg} / \text { mean } \\ & \text { of right and left arm) }\end{aligned}$

of right and left arm)

Systoric

Digastric

Hear rate(beat/minutes)

Right
40.1
$(7.9)$

(7.9)

35.0

(3.1)
0.551

0.494

33.6
(3.0)

33.5

(3.0)$$
\text { . }
$$

\begin{tabular}{ll}
33.8 & $* 0.023$ \\
$(2.9)$ & \\
33.9 & $* 0.031$ \\
$(3.1)$ & \\
\hline
\end{tabular}

\begin{tabular}{llllll|}
\hline 133.3 & 133.2 & 0.986 & $\begin{array}{l}130.1 \\
(18.5)\end{array}$ & $\begin{array}{l}131.8 \\
(13.0)\end{array}$ & 0.626 \\
\hline 78.3$)$ & $(23.0)$ & & & \\
\hline$(16.9)$ & 76.8 & 0.309 & 69.6 & 70.1 & 0.474 \\
\hline & $(16.3)$ & & $(10.8)$ & $(10.4)$ & \\
\hline
\end{tabular}

\section{Performance assessment}

Tongue pressure $\begin{array}{ll}39.2(8.2) & 40.1 \\ & (7.9)\end{array}$

81.0
$(10.8)$

0.524

76.8

(9.6)

76.1

(9.0)

0.635

(13.5)

Grip strength (mean of right and left arms)

\begin{tabular}{|c|c|c|c|c|c|c|}
\hline Right arm (kg) & $30.0(8.1)$ & $\begin{array}{l}30.2 \\
(7.3)\end{array}$ & 0.818 & $\begin{array}{l}25.4 \\
(6.7)\end{array}$ & $\begin{array}{l}25.4 \\
(6.9)\end{array}$ & 0.928 \\
\hline Left $\operatorname{arm}(\mathrm{kg})$ & $27.2(6.8)$ & $\begin{array}{l}27.5 \\
(6.6)\end{array}$ & 0.637 & $\begin{array}{l}25.4 \\
(6.9)\end{array}$ & $\begin{array}{l}23.3 \\
(6.0)\end{array}$ & 0.099 \\
\hline OLST total $120, \mathrm{n}(\%)$ & $21(58.3)$ & $\begin{array}{l}20 \\
(55.6)\end{array}$ & 1.000 & $\begin{array}{l}11 \\
(29.7)\end{array}$ & $\begin{array}{l}13 \\
(35.1)\end{array}$ & 0.804 \\
\hline 3.0-m walking (second) & $1.7(0.2)$ & $1.6(0.2)$ & $\star 0.012$ & $\begin{array}{l}1.7 \\
(0.3)\end{array}$ & $\begin{array}{l}1.7 \\
(0.3)\end{array}$ & 0.225 \\
\hline
\end{tabular}

OLST, One-leg standing test with eye open; VC, vital capacity; FVC, forced vital capacity; $F_{E V}{ }_{1.0}$, forced expiratory volume in 1 second; 3.0-m TUG, timed 2.4 meter up-and-go test; CS-30, 30-second chair stand test. * $p<0.05$ 


\begin{tabular}{|c|c|c|c|c|c|c|}
\hline & \multicolumn{2}{|l|}{$\begin{array}{l}\text { Age, } \leq 70 \\
n=36\end{array}$} & & \multicolumn{2}{|c|}{$\begin{array}{l}\text { Age, } \geq 71 \\
n=37\end{array}$} & \multirow[b]{2}{*}{$(0.022)$} \\
\hline TUG (usually) (second) & $7.5(1.2)$ & $7.4(1.2)$ & 0.707 & $\begin{array}{l}7.5 \\
(1.2)\end{array}$ & $\begin{array}{l}7.8 \\
(1.3)\end{array}$ & \\
\hline TUG (fast) (second) & $5.7(0.9)$ & $5.7(0.6)$ & 0.453 & $\begin{array}{l}6.3 \\
(0.8)\end{array}$ & $\begin{array}{l}6.1 \\
(0.9)\end{array}$ & 0.355 \\
\hline CS-30 (times) & $23.4(5.6)$ & $\begin{array}{l}24.7 \\
(5.9)\end{array}$ & 0.042 & $\begin{array}{l}21.0 \\
(5.9)\end{array}$ & $\begin{array}{l}22.4 \\
(7.3)\end{array}$ & *0.020 \\
\hline MOCA-J (points) & $28.0(2.1)$ & $\begin{array}{l}28.1 \\
(1.9)\end{array}$ & 0.782 & $\begin{array}{l}26.0 \\
(3.0)\end{array}$ & $\begin{array}{l}26.1 \\
(3.1)\end{array}$ & 0.772 \\
\hline$\leq 26 \mathrm{~W} \mathbb{\mathrm { N }} \mathrm{n}(\%)$ & $32(88.9)$ & $\begin{array}{l}32 \\
(88.9)\end{array}$ & 1.000 & $\begin{array}{l}24 \\
(64.9)\end{array}$ & $\begin{array}{l}25 \\
(67.6)\end{array}$ & 1.000 \\
\hline \multicolumn{7}{|l|}{ Standing position balance } \\
\hline \multicolumn{7}{|l|}{ Opened eyes } \\
\hline Area $\left(\mathrm{cm}^{2}\right)$ & $\begin{array}{l}4.48 \\
(1.94)\end{array}$ & $\begin{array}{l}4.88 \\
(2.67)\end{array}$ & 0.502 & $\begin{array}{l}4.29 \\
(2.69)\end{array}$ & $\begin{array}{l}4.03 \\
(2.16)\end{array}$ & 0.451 \\
\hline Speed (cm/second) & $\begin{array}{l}1.76 \\
(0.47)\end{array}$ & $\begin{array}{l}1.80 \\
(0.47)\end{array}$ & 0.655 & $\begin{array}{l}1.73 \\
(0.48)\end{array}$ & $\begin{array}{l}1.82 \\
(0.68)\end{array}$ & 0.186 \\
\hline Congestion (1/cm) & $\begin{array}{l}27.14 \\
(11.02)\end{array}$ & $\begin{array}{l}27.76 \\
(13.42)\end{array}$ & 0.820 & $\begin{array}{l}29.0 \\
(11.37)\end{array}$ & $\begin{array}{l}30.26 \\
(9.85)\end{array}$ & 0.401 \\
\hline Center left and right $(\mathrm{cm})$ & $\begin{array}{l}0.05 \\
(0.52)\end{array}$ & $\begin{array}{l}-0.10 \\
(0.66)\end{array}$ & 0.177 & $\begin{array}{l}-0.13 \\
(0.90)\end{array}$ & $\begin{array}{l}-0.04 \\
(0.63)\end{array}$ & 0.639 \\
\hline Center front and rear $(\mathrm{cm})$ & $\begin{array}{l}-0.56 \\
(1.69)\end{array}$ & $\begin{array}{l}-0.13 \\
(0.90)\end{array}$ & $\star 0.012$ & $\begin{array}{l}-0.13 \\
(0.63)\end{array}$ & $\begin{array}{l}-0.23 \\
(1.20)\end{array}$ & 0.706 \\
\hline Area Long Berg rate & $\begin{array}{l}1.33 \\
(0.49)\end{array}$ & $\begin{array}{l}1.27 \\
(0.49)\end{array}$ & 0.762 & $\begin{array}{l}1.33 \\
(0.80)\end{array}$ & $\begin{array}{l}1.35 \\
(0.49)\end{array}$ & 0.889 \\
\hline Short area $\left(\mathrm{cm}^{2}\right)$ & $\begin{array}{l}10.53 \\
(4.58)\end{array}$ & $\begin{array}{l}11.79 \\
(6.06)\end{array}$ & 0.351 & $\begin{array}{l}10.49 \\
(7.27)\end{array}$ & $\begin{array}{l}9.03 \\
(5.72)\end{array}$ & 0.086 \\
\hline Rms value area $\left(\mathrm{cm}^{2}\right)$ & $\begin{array}{l}2.39 \\
(1.58)\end{array}$ & $\begin{array}{l}2.35 \\
(1.36)\end{array}$ & 0.923 & $\begin{array}{l}2.00 \\
(5.73)\end{array}$ & $\begin{array}{l}1.84 \\
(1.08)\end{array}$ & 0.482 \\
\hline Total track length $(\mathrm{cm})$ & $\begin{array}{l}100.29 \\
(36.83)\end{array}$ & $\begin{array}{l}108.03 \\
(29.24)\end{array}$ & 0.168 & $\begin{array}{l}103.56 \\
(28.57)\end{array}$ & $\begin{array}{l}108.93 \\
(40.63)\end{array}$ & 0.195 \\
\hline
\end{tabular}

OLST, One-leg standing test with eye open; VC, vital capacity; FVC, forced vital capacity; $F_{E V}{ }_{1.0}$, forced expiratory volume in 1 second; 3.0-m TUG, timed 2.4 meter up-and-go test; CS-30, 30-second chair stand test. * $p<0.05$ 


\begin{tabular}{|c|c|c|c|c|c|c|}
\hline \multirow{2}{*}{ Area $\left(\mathrm{cm}^{2}\right)$} & \multicolumn{2}{|l|}{$\begin{array}{l}\text { Age, } \leq 70 \\
n=36\end{array}$} & & \multicolumn{3}{|c|}{$\begin{array}{l}\text { Age, } \geq 71 \\
\mathrm{n}=37\end{array}$} \\
\hline & $5.81(2.87)$ & $\begin{array}{l}5.28 \\
(2.20)\end{array}$ & 0.177 & $\begin{array}{l}5.23 \\
(3.43)\end{array}$ & $\begin{array}{l}5.34 \\
(3.38)\end{array}$ & 0.823 \\
\hline Speed (cm/second) & $\begin{array}{l}2.52 \\
(0.95)\end{array}$ & $\begin{array}{l}2.30 \\
(0.73)\end{array}$ & 0.148 & $\begin{array}{l}2.50 \\
(1.25)\end{array}$ & $\begin{array}{l}2.52 \\
(1.18)\end{array}$ & 0.778 \\
\hline Congestion $(1 / \mathrm{cm})$ & $\begin{array}{l}30.48 \\
(12.93)\end{array}$ & $\begin{array}{l}29.68 \\
(12.48)\end{array}$ & 0.652 & $\begin{array}{l}32.55 \\
(11.59)\end{array}$ & $\begin{array}{l}32.23 \\
(11.65)\end{array}$ & 0.870 \\
\hline Center left and right $(\mathrm{cm})$ & $\begin{array}{l}0.09 \\
(0.65)\end{array}$ & $\begin{array}{l}-0.16 \\
(1.78)\end{array}$ & $\star 0.039$ & $\begin{array}{l}-0.12 \\
(0.67)\end{array}$ & $\begin{array}{l}-0.10 \\
(0.77)\end{array}$ & 0.935 \\
\hline Center front and rear $(\mathrm{cm})$ & $\begin{array}{l}-0.08 \\
(1.78)\end{array}$ & $\begin{array}{l}-0.82 \\
(1.00)\end{array}$ & $* 0.021$ & $\begin{array}{l}0.24 \\
(1.61)\end{array}$ & $\begin{array}{l}0.11 \\
(1.26)\end{array}$ & 0.650 \\
\hline Area Long Berg rate & $\begin{array}{l}14.58 \\
(7.59)\end{array}$ & $\begin{array}{l}13.05 \\
(5.09)\end{array}$ & 0.298 & $\begin{array}{l}12.97 \\
(8.91)\end{array}$ & $\begin{array}{l}11.76 \\
(6.78)\end{array}$ & 0.264 \\
\hline Short area $\left(\mathrm{cm}^{2}\right)$ & $\begin{array}{l}2.45 \\
(1.17)\end{array}$ & $\begin{array}{l}2.25 \\
(0.96)\end{array}$ & 0.118 & $\begin{array}{l}2.20 \\
(1.40)\end{array}$ & $\begin{array}{l}2.20 \\
(1.26)\end{array}$ & 0.950 \\
\hline Rms value area $\left(\mathrm{cm}^{2}\right)$ & $\begin{array}{l}151.23 \\
(56.81)\end{array}$ & $\begin{array}{l}138.17 \\
(43.83)\end{array}$ & 0.151 & $\begin{array}{l}149.71 \\
(75.30)\end{array}$ & $\begin{array}{l}151.51 \\
(70.53)\end{array}$ & 0.773 \\
\hline \multicolumn{7}{|c|}{$\begin{array}{l}\text { OLST, One-leg standing test with eye open; VC, vital capacity; FVC, forced vital capacity; FEV }{ }_{1.0} \text {, forced } \\
\text { expiratory volume in } 1 \text { second; } 3.0 \text {-m TUG, timed } 2.4 \text { meter up-and-go test; CS-30, 30-second chair } \\
\text { stand test. * } p<0.05\end{array}$} \\
\hline
\end{tabular}

\section{Performance}

Performance measurement data are shown in the middle third of Table 3. In general, the results tended to show slight worsening in younger participants and improvement in older participants. Although the difference was not significant, tongue pressure tended to increase.

Grip strength slightly increased in the younger group, but the difference was not significant.

Figure 2 shows the graphs of individual changes in normal walking $(a, b)$ and rapid walking (c, d) in TUG and CS-30 performance $(e, f)$ before and after intervention are shown for participants younger and older than 70 years. There was substantial variation in all datasets, with some participants exhibiting improved performance and others exhibiting decreased performance.

The usual speed in each trial of the TUG of participants aged $\geq 71$ years was slower than younger. Examining individual changes (Fig.

2) in TUG performance, for both walking at normal speed and while walking fast, revealed that the time taken by younger participants was shorter in many cases. 
There was a marked improvement in CS-30 performance, particularly among participants aged $\geq 71$ years, performing a significantly greater number of chair stands following the intervention.

Examining individual data revealed that, regardless of the number of chair stands before the intervention, each participant completed more chair stands in 30 seconds after the intervention (Fig.

2).

Regarding cognition, no significant changes resulted from the intervention; $10 \%$ of participants exhibited mild cognitive impairment, with a MOCA-J test score of 26 points or less. ${ }^{12}$

\section{Standing position balance}

The data acquisition and analysis of sway of the center of gravity using the Gravicorder are shown in the lower third of Table 3. The center-of-gravity sway meter showed no general tendency toward change. Changes in the front-rear and left-right center of gravity with eyes closed in the younger group were aggravated after the intervention. Examining individuals' data (not shown) revealed substantial variability among individuals, with some individuals exhibiting improvement after the intervention, and others showing no improvement. This variation was more prominent in older participants.

\section{Discussion}

To prevent the onset and progression of frailty syndrome, multi-factorial exercise programs can be effective, including resistance exercise, balance training, and functional training health in older adults who live in the community. In addition, fall-rate reduction has been reported through a combination of balance exercise, functional exercise, and resistance exercise [5] [6]. In addition to multi-factorial exercise, intensified training with trainers [7] or multi-professional teams [8] could lead to optimal effects.

Although AWs are used in gymnastics classes for older adults in some areas of Japan, there are various risks involved, and no guidelines currently exist for safe personal use by older individuals.

AWs have been found to have a beneficial effect on gait factors when properly used by healthy adults[9]. However, the effects of simple programs, including resistance training to prevent falls, dance and walking, are unknown [10].

Because we targeted older people living in the community, there was a relatively low change of falling, and our outcomes were focused on frailty prevention, particularly muscle strengthening effects.

The effectiveness of measures to improve locomotor function among older people has been reported using elastic bands [11], iron arrays [12], and machine-based muscle strengthening exercises [13].

In an intervention using AWs in healthy older women, performing muscle strengthening of the lower limbs using an elastic band and AWs three times a week for 12 weeks, including an instruction session once a week, resulted in a significant improvement in isometric knee extension muscle strength, isometric elbow 
flexion muscle strength, grip force, and weight ratio leg extension power, but no improvement in movement ability, such as standing up and stepping up/down [14].

The recent prevalence of the COVID-19 pandemic has led to a decrease in exercise classes with instructors.

In future, the utilization of internet technology including video, remote instruction and virtual reality may be important as effective substitutes for face-to-face classes with a trainer [7] or multi-professional team [8]. Thus, it is important to investigate safe and sustainable exercise environments at home. The current study produced primary data verifying the effect of AWs as a wearable muscle load device. We sought to contribute to the development of environments in which exercise can be safely continued at home with AWs. However, depending on the method employed, this approach could cause health problems, and some products warn against use by older adults alone. There is currently no specified safe environment for older adults to voluntarily incorporate AWs as a frailty prevention measure.

In the current study, we implemented a 3-month intervention with minimum requirements of use during the intervention period.

Data regarding usage frequency and pre-falling incidents, obtained from sensors attached to AWs or selfrecording, were not connected to individual anthropometry and performance data.

Thus, the current study is considered an interim report in a larger project. There were no serious accidents or incidents during the study period, and the AW intervention induced significant increases in lower limb circumference and CS-30 performance in older subjects, verifying the beneficial effects of the AW intervention on strengthening lower limb muscle.

Compared with other intervention studies [14] [15], the focus of the current study was not strict, and the sample size was not sufficient.

Nevertheless, the lower leg circumference of older participants and CS-30 performance in both groups exhibited a significant improvement.

A previous study reported that the CS-30 is a highly reproducible test that is significantly correlated with leg extension muscle strength, and can be used to evaluate lower extremity muscle strength among people aged 60 years and over living in the community [4]. Figure 2 shows that, although there was no overall improvement, there was an average trend toward improvement, and it is possible that differences in individual effort are reflected in the measured values after the intervention. No improvement was observed in other performance items. In TUG, some studies have reported positive effects [16] while other studies have reported negative effects [17]. In future studies, it would be useful to collate each individual's sensor data and activity diary with these measurement data.

Although no significant differences were observed in bilateral lower limbs, trunk muscle mass (Table 2), or tongue pressure (Table 3), future studies should conduct trials with a longer intervention period and more participants. The sway of the center of gravity also integrates complex functions, such as deep 
sensation and the extrapyramidal tract, and improvement is not only exhibited by improvement of lower limb strength. Previous studies have reported that gravity changes are not directly affected by muscle strength [18] [19] [17] [20].

Considering the attachment site of AWs, the load would be expected to particularly affect the swing motion of the lower limbs and the flexion motion of the hip joint during walking motion. These movements tend to be weakened with aging, and if additional stress can be selectively applied to these movements, it could not only serve as an exercise load but also suppress the deterioration of walking function among older people. It is also possible that this method could be applied as a high-quality exercise therapy.

Because the study regime was not strict, various factors may have affected individual effort.

Furthermore, it was difficult to control for confounding factors, such as the effects of participating in regular individual exercise classes and sports activity, such as yoga and personal gym use.

Currently, while staying at home to contain the COVID-19 pandemic, inactivity among older people has become a serious problem. Frailty prevention approaches are moving toward self-restraint and outdoor activities that avoid close contact. Outdoor activities such as walking while avoiding contact with others are preferred options for strengthening physical fitness. Walking has been widely adopted for physical strengthening. However, although walking may have an effect on improving cardiopulmonary function, it has been reported to have little effect on muscle strengthening and fall prevention [21]. However, incorporation of walking combined with wearing AWs has the potential to be effective for lower limb muscle strengthening. In the case of older adults, however, because there is a large difference in individual abilities, it is necessary to propose measures that are suitable for each individual's physical characteristics, muscle mass, muscle strength, and exercise abilities. To provide feedback, a system for formulating a menu that suits each individual according to guidelines for proper use would be useful.

Finally, one participant remarked that taking part in the study motivated them to exercise, and to walk. This comment suggests the importance of fostering and maintaining motivation in healthy older adults.

The present study involved several limitations. First, it is difficult to conduct ideal exercise intervention research in older adults' daily lives. Therefore, various data regarding daily activity and AW-wearing records that we intended to collect were not possible to measure in this study. It would be valuable for future studies to develop a research system that collects and collates these data sources automatically.

We asked participants to select the wearing conditions of AWs according to the appropriate situation for each individual and advised a minimum use requirement of 20 minutes at least once to twice per week. However, it was difficult for some participants to understand the self-administration conditions.

\section{Conclusion}


The present study revealed significant increases in lower limb circumference and CS-30 performance in older subjects, indicating improved lower limb/trunk muscle strength. These results suggest that wearing AWs can be recommended as an easy method for strengthening lower limbs. In addition, our findings suggest that investigating a research system to collect and collate these data automatically may be a valuable next step.

\section{List Of Abbreviations}

Coronavirus disease 2019 (COVID-19)

Motor Fitness Scale (MFS)

30-second chair stand test (CS-30)

Timed up-and-go test (TUG)

Japanese version of Montreal Cognitive Assessment (MOCA-J)

Ankle weights (AWs)

The Community Health Education and Research Center (CHC)

University hospital Medical Information Network (UMIN)

Skeletal muscle mass index (SMI)

One-leg standing test (OLST)

Dual Energy X-ray Absorptiometry (DEXA)

Magnetic resonance imaging (MRI)

Standard deviation (SD)

Asian Working Group for Sarcopenia (AWGS)

Japan Agency for Medical Research and Development (AMED)

\section{Declarations}

\section{Ethics approval and consent to participate}

This study was carried out according to the Helsinki Declaration and all methods were carried out in accordance with relevant guidelines and regulations. And the study was approved by the Ethics Committee of Nagoya City University (approval number 46-19-0010; August 13th, 2019). Informed 
consent from participants was obtained just before the pre-observation period after an information session and MFS Survey.

\section{Consent for publication}

Not applicable.

\section{Availability of data and materials}

All relevant data are included in the paper and its Supporting Information file.

\section{Competing interests}

The authors declare no conflict of interest without research funding from AMED.

\section{Funding}

The study was supported by the Japan Agency for Medical Research and Development (AMED) from the "Research program for health behavior modification by using IoT" under Grant Number JP19le0110012. The funders had no role in the design, methods, participant recruitment, or data collection in this study.

\section{Authors' contributions}

\section{H.A.: Total planning and management}

T. M.: Data analysis

Y. K., Y. M., S. H., T. J., and S. K.: Recruitment of participants and holding of measurement sessions.

T. H., H.O.: Assisting management and supervision.

\section{Acknowledgments}

We thank all participants for participating in our study. We thank our staff Ms. Yuko Kimura, Emiko Yoshino, Atsuko Takeyama and Kumiko Suzuki for assistance with venue setting and measurement, and Ms. Serika Nakamura for assisting with data entry. We thank Mr. Keigo Mori and Mr. Toshiharu Nakagawa for assistance with measurement. We also thank Benjamin Knight, MSc., from Edanz Group (https://en-author-services.edanz.com/ac) for editing a draft of this manuscript.

\section{References}

1. Graves JE, Martin AD, Miltenberger LA, Pollock ML: Physiological responses to walking with hand weights, wrist weights, and ankle weights. Med Sci Sports Exerc 1988, 20(3):265-271.

2. Barnett SL, Bagley AM, Skinner HB: Ankle weight effect on gait: orthotic implications. Orthopedics 1993, 16(10):1127-1131. 
3. Sugiura $Y$, Tanimoto $Y$, Watanabe M, Tsuda Y, Kimura M, Kusabiraki T, Kono K: Handgrip strength as a predictor of higher-level competence decline among community-dwelling Japanese elderly in an urban area during a 4-year follow-up. Arch Gerontol Geriatr 2013, 57(3):319-324.

4. Jones CJ, Rikli RE, Beam WC: A 30-s chair-stand test as a measure of lower body strength in community-residing older adults. Res Q Exerc Sport 1999, 70(2):113-119.

5. Weening-Dijksterhuis E, de Greef MH, Scherder EJ, Slaets JP, van der Schans CP: Frail institutionalized older persons: A comprehensive review on physical exercise, physical fitness, activities of daily living, and quality-of-life. Am J Phys Med Rehabil 2011, 90(2):156-168.

6. Daniels R, van Rossum E, de Witte L, Kempen GI, van den Heuvel W: Interventions to prevent disability in frail community-dwelling elderly: a systematic review. BMC Health Serv Res 2008, 8:278.

7. Binder EF, Schechtman KB, Ehsani AA, Steger-May K, Brown M, Sinacore DR, Yarasheski KE, Holloszy JO: Effects of exercise training on frailty in community-dwelling older adults: results of a randomized, controlled trial. J Am Geriatr Soc 2002, 50(12):1921-1928.

8. Cameron ID, Fairhall N, Langron C, Lockwood K, Monaghan N, Aggar C, Sherrington C, Lord SR, Kurrle SE: A multifactorial interdisciplinary intervention reduces frailty in older people: randomized trial. BMC Med 2013, 11:65.

9. Hwang JW, Lee SK, Park JS, Ahn SH, Lee KJ, Lee SJ: The effects of ankle weight loading on the walking factors of adults without symptoms. J Exerc Rehabil 2017, 13(4):425-429.

10. Sherrington C, Fairhall N, Wallbank G, Tiedemann A, Michaleff ZA, Howard K, Clemson L, Hopewell S, Lamb S: Exercise for preventing falls in older people living in the community: an abridged Cochrane systematic Review. Br J Sports Med 2019.

11. Jette AM, Lachman M, Giorgetti MM, Assmann SF, Harris BA, Levenson C, Wernick M, Krebs D: Exercise-it's never too late: the strong-for-life program. Am J Public Health 1999, 89(1):66-72.

12. Sevick MA, Bradham DD, Muender M, Chen GJ, Enarson C, Dailey M, Ettinger WH, Jr.: Costeffectiveness of aerobic and resistance exercise in seniors with knee osteoarthritis. Med Sci Sports Exerc 2000, 32(9):1534-1540.

13. Buchner DM, Cress ME, de Lateur BJ, Esselman PC, Margherita AJ, Price R, Wagner EH: The effect of strength and endurance training on gait, balance, fall risk, and health services use in communityliving older adults. J Gerontol A Biol Sci Med Sci 1997, 52(4):M218-224.

14. Skelton DA, Young A, Greig CA, Malbut KE: Effects of resistance training on strength, power, and selected functional abilities of women aged 75 and older. J Am Geriatr Soc 1995, 43(10):1081-1087.

15. Latham NK, Anderson CS, Lee A, Bennett DA, Moseley A, Cameron ID, Fitness Collaborative G: A randomized, controlled trial of quadriceps resistance exercise and vitamin $D$ in frail older people: the Frailty Interventions Trial in Elderly Subjects (FITNESS). J Am Geriatr Soc 2003, 51(3):291-299.

16. Lustosa LP, Silva JP, Coelho FM, Pereira DS, Parentoni AN, Pereira LS: Impact of resistance exercise program on functional capacity and muscular strength of knee extensor in pre-frail communitydwelling older women: a randomized crossover trial. Rev Bras Fisioter 2011, 15(4):318-324. 
17. Chou $\mathrm{CH}$, Hwang $\mathrm{CL}$, Wu YT: Effect of exercise on physical function, daily living activities, and quality of life in the frail older adults: a meta-analysis. Arch Phys Med Rehabil 2012, 93(2):237-244.

18. Horak FB: Clinical measurement of postural control in adults. Phys Ther 1987, 67(12):1881-1885.

19. Woollacott MH, Shumway-Cook A, Nashner LM: Aging and posture control: changes in sensory organization and muscular coordination. Int J Aging Hum Dev 1986, 23(2):97-114.

20. Gine-Garriga M, Roque-Figuls M, Coll-Planas L, Sitja-Rabert M, Salva A: Physical exercise interventions for improving performance-based measures of physical function in communitydwelling, frail older adults: a systematic review and meta-analysis. Arch Phys Med Rehabil 2014, 95(4):753-769 e753.

21. Ganz DA, Latham NK: Prevention of Falls in Community-Dwelling Older Adults. N Engl J Med 2020, 382(8):734-743.

\section{Figures}

Fig. 1

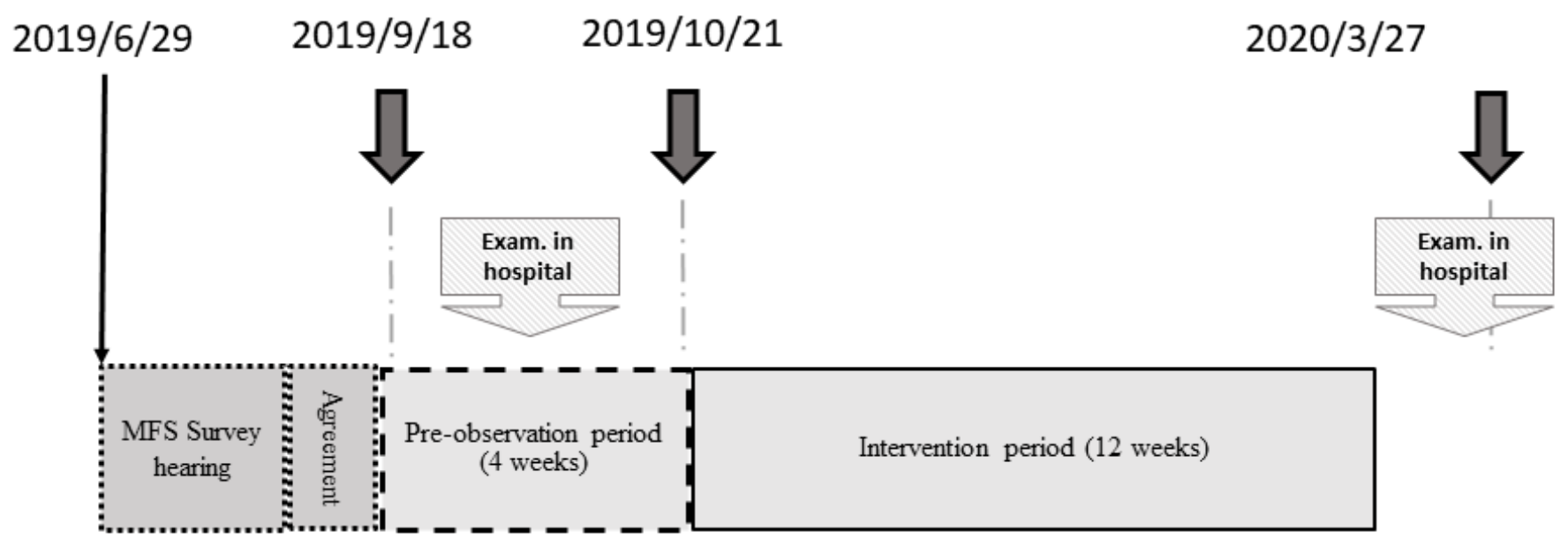

Renting personal

activity meter

Renting AW with accelerometer sensor and memory, and diary to record activity

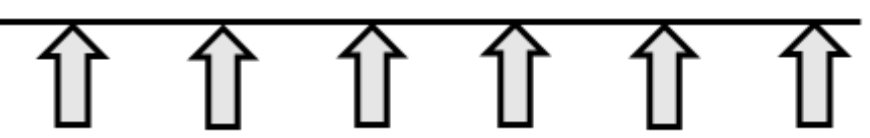

Physical/body measurement Cognitive function

accelerometer memory up-load, diary description check and feedback Group I

Exam. in hospital

Blood biochemical test, respiratory function and abdominal magnetic resonance imaging (MRI)

Figure 1 
Flowchart of prospective intervention test. After obtaining consent, conducting the Motor Fitness Scale (MFS), and collecting participants' clinical history, the first measurements were performed. After observation for 4 weeks, further measurements were performed (2nd), followed by the intervention for 12 weeks. The final measurement was performed after the intervention (3rd). In the current study, we analyzed the data before (2nd) and after (3rd) the intervention. MFS, Motor Fitness Scale.

Fig. 2

Among participants aged $\leq 70$ years

a. TUG (usually)

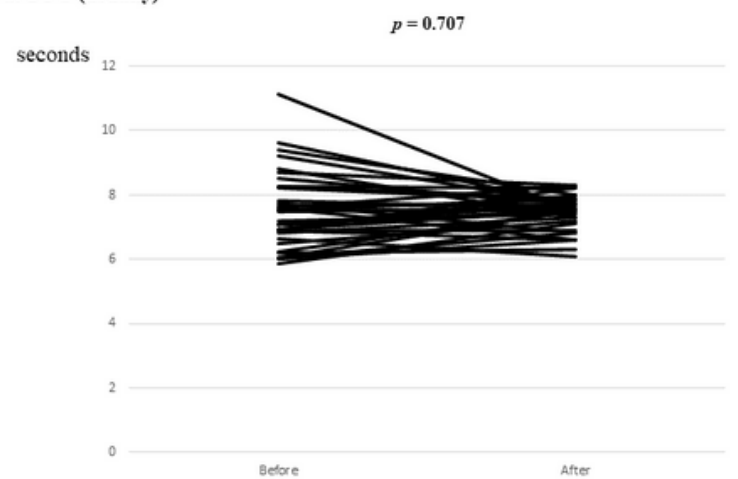

c. TUG (fast)

seconds

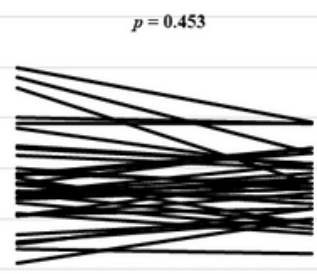

Betore

e. CS-30

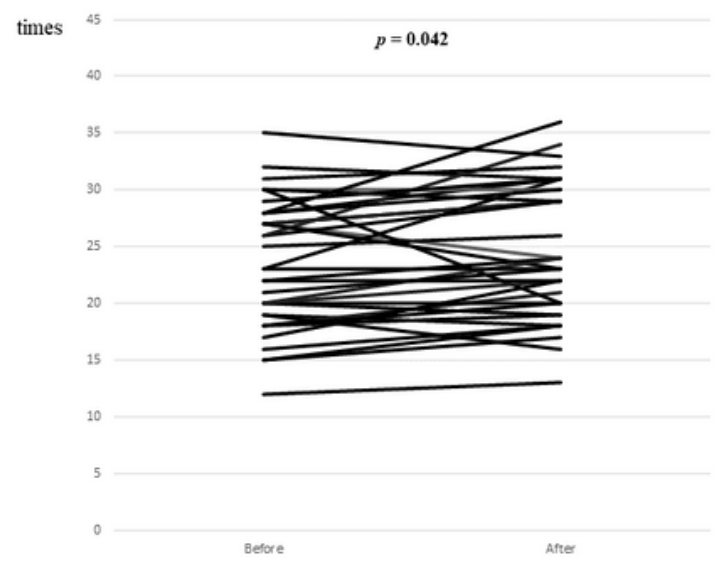

Among participants aged $\geq 71$ years

b. TUG (usually)

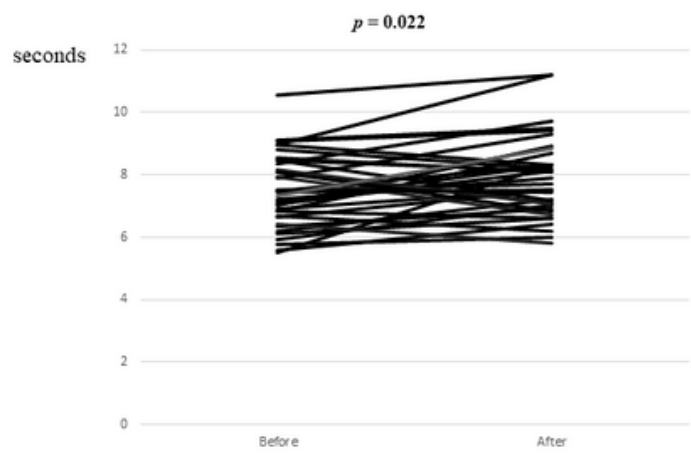

d. TUG (fast)

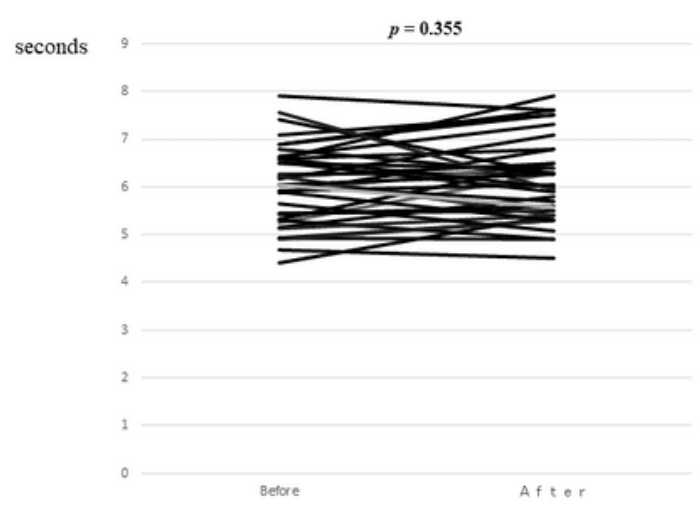

f. CS-30

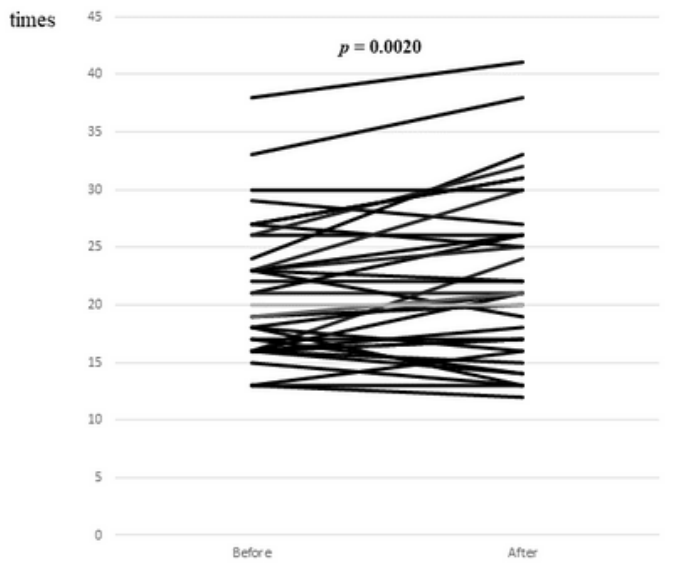

Figure 2 
Graphs of individual changes in normal walking $(a, b)$ and rapid walking $(c, d)$ in TUG and CS-30 performance $(e, f)$ before and after intervention are shown for participants younger and older than 70 years. There was substantial variation in all datasets, with some participants exhibiting improved performance and others exhibiting decreased performance. However, many participants showed relative improvement in CS-30 performance. TUG, timed up-and-go test; CS-30, 30-second chair stand test.

\section{Supplementary Files}

This is a list of supplementary files associated with this preprint. Click to download.

- HAsupplement.pptx 